\title{
The role of carbon nanotubes in antibiotics drug delivery
}

\author{
Ghodsi Mohammadi Ziarani ${ }^{*}$, Shadi Tahmasebi Ashtiani ${ }^{1}$, Fatemeh Mohajer ${ }^{1}$ and Alireza Badiei ${ }^{2}$ \\ ${ }^{1}$ Department of Chemistry, Faculty of Physics and Chemistry, Alzahra University, Tehran, Iran \\ ${ }^{2}$ School of Chemistry, College of Science, University of Tehran, Tehran, Iran
}

\begin{abstract}
Carbon nanotubes (CNTs) have a tremendous role as nanocarriers in the area of drug delivery, due to their high surface area and ability to be easily conjugated with many organic and drug groups like anticancer, antibiotics, etc. This review has reported the role of the functionalized CNTs in antibiotics drug delivery from 2017 to 2019 .
\end{abstract}

\begin{abstract}
Abbreviatations
CNT: Carbon Nanotube; THF: Tetrahydrofuran; SWCNT: Singlewalled Carbon Nanotube; $o$-DCB: Orthodichlorobenzene; MWCNT: Multi-walled Carbon Nanotube; DMF: Dimethylformamide; DDS: Drug delivery system; PTFE: Polytetrafluoroethylene; PDMS: Polydimethylsiloxane; IC: Ion chromatography; CVD: Chemical vapor deposition; MW : Microwave; TFA: Trifluoroacetic acid; DI: Deionized; MB: Methylene blue; aPDT: Antimicrobial photodynamic therapy; HAS: Human serum albumin; $f$-MWCNTs: Functionalized multiwalled Carbon Nanotubes; SnOct2: Stannous octoate; Doxy: $\alpha$-6-deoxy5-oxytetracycline; PCL: Poly( $\varepsilon$-caprolactone); SMZ: Sulfamethoxazole; MG: Malachite green; PEG: Poly(ethylene glycol); $\varepsilon$-CL: $\varepsilon$-caprolactone; PTOL: Pentaery-thritol; LVF: Levofloxacin; OxCl: Oxalyl chloride; EDMA: Ethylene glycol dimethacrylate; VA: 9-vinyl anthracene; AIBN: 2,2-Azobis (2-isobutyronitrile); MAA: Methacrylic acid; LC-MIPs: Liquid crystalline molecularly imprinted polymers; MPDE: 4-Methyl phenyl dicyclohexyl ethylene; DCC: $N, N^{\prime}$-dicyclohexylcarbodiimide; GRDDS: Gastro retentive drug delivery system; MIC: Minimal inhibitory concentration; H2TriMAPP: 5,10,15-Triphenyl-20(4-aminophenyl)-porphyrin; VLS: Vapor-liquid-solid; NPs: Nanoparticles; CMCS: Carboxymethyl chitosan; AB: Antibiotic; AAM: Acrylamide; PECVD: Plasma-enhanced chemical vapor deposition; CUR: Curcumin MCA Monochloroacetic acid; APS: Ammonium persulfate; PEGDMA: Polyethylene glycol dimethacrylate; DMAP: Dimethyl aminopyridine; Gel: Gelatin; DCM: Dichloromethane; TEG: Triethylene glycol; DIPEA: N,N-diisopropylethylamine; EDC: 1-Ethyl3-(3-dimethylaminopropyl)-carbodiimide; Boc2O: Di-tert-butyl decarbonate; HEG: Hexaethylene glycol; DMSO: Dimethyl sulfoxide.
\end{abstract}

\section{Introduction}

The important goal of enhancing nanocarrier drug delivery systems (DDS) is to develop the therapeutic impact or decrease the toxicity of medically active compounds [1]. Carbon nanotubes (CNTs) discovered by Iijima in 1991, are structures with nanometric diameters [2,3]. There are two types of carbon nanotubes, including single-walled (SWCNTs) and multi-walled carbon nanotubes (MWCNTs). Carbon nanotubes have significant properties, including remarkable electrical conductivity, exceptional tensile strength, thermal conductivity, and the ability to be modified chemically $[4,5]$. Carbon nanotubes features, including unique surface area, stiffness, strength, and resilience, have led to much interest in the field of drug delivery systems. Also, nanomaterials like CNTs have been employed in different applications such as DNA detection and the improvement of immunoassays for the bacteria detection [6]. CNTs are exposed to adsorb or conjugate with a wide kind of therapeutic materials such as bioactive proteins, peptides, and drugs because of their high surface area. These systems have a splendid potential in the nanomedicine field because functionalized CNTs show low toxicity and not to disturb immune systems [7]. Drug delivery refers to methods, formulations, technology fields, and systems for carrying a pharmaceutical composite in the body, sometimes based on nano compounds such as CNTs [8]. DDS like lipid- or polymerbased nano compounds could be aimed to improve the pharmacologic and therapeutics features of drugs controlled parenterally [9]. Two functionalization methods are used for the modification of CNTs (SWCNTs 1, MWCNTs 2) (Scheme 1). CNTs are able to be oxidized employing strong acids, and as a result, their length reducts while forming carboxylic groups, which improve their dispersion in aqueous solutions [10]. Dissolvability under physiological situations is a key precondition to gain CNTs biocompatible. Furthermore, functionalized CNTs ( $f$-CNTs) 3 or 4 can be bonded to different active molecules, such as proteins, peptides, nucleic acid, and other medical agents. CNTs eternal walls can be functionalized by an efficient method in regard to the 1,3-dipolar cycloaddition of azomethine ylides. CNTs go through the addition reaction while warmed in DMF in front of an aldehyde and an $\alpha$-amino acid [11]. The rang of this reaction is extremely wide and forms $f$-CNTs $\mathbf{5}$ or $\mathbf{6}$, which have high solubility in an extensive scope of solvents. It can be possible to adjust solubility in aqueous solutions of organic solvents by attentively selecting the reactants [12].

Antibiotics has had a significant effect on human and animals life with the ability of controlling infections during the past century [13].

${ }^{\star}$ Correspondence to: Ghodsi Mohammadi Ziarani, Department of Chemistry, Faculty of Physics and Chemistry, Alzahra University, Tehran, Iran, P.O. Box: 1993893973 Tel: +98 2186613937, E-mail: gmohammadi@alzahra.ac.ir

Keywords: carbon nanotubes (CNTs), antibiotic drugs, functionalized carbon nanotubes, drug delivery

Received: December 28, 2020; Accepted: January 18, 2021; Published: January 22,2021 
Weak antibiotic internalization can be solved by carring antibiotics with nanomaterials such as CNTs which are able to effectively interact with the bacterial envelopments [14].

In continuous our previous work [15-22] the role of carbon nanotubes in antibiotics drugs delivery is reviewed.

\section{The synthesis of functionalized single-walled carbon nanotubes ( $f$-SWCNTs) SWCNTs functionalized by thioglycoside derivatives}

The reaction of 4-Ethynylaniline 7 with di-tert-butyldicarbonate provided tert-butyl(4-ethynylphenyl)carbamate 8 , which reacted with azide composition (mannose) 11 or (lactose) 12 respectively in the presence of sodium $L$-ascorbate and copper sulfate in water to produce 1,4-disubstituted triazole 13 or 14 . The deprotection of compound 13 or 14 by treatment with trifluoroacetic acid (TFA) produced the compound 15 or 16 , which was treated with a mixture of $\mathrm{MeONa} /$ $\mathrm{MeOH}$ to obtain the neutral amine 17 or 18 (Scheme 2) [23].

The mixture of fresh poly(1-vinyl-3-butylimidazolium chlorideco-1-vinylimidazole) (P2)-SWCNTs 19 and amines (mannose) 17 or (lactose) 18 was dispersed in ortho dichlorobenzene (o-DCB) and dimethylformamide (DMF) under ultrasonic condition. To this mixture, iso-amylnitrite was added to generate $f$-SWCNTs 20 or 21 through the hydrolyzation reaction (Scheme 3). Then, their capabilities were tested for agglutination and selective inhibition of the uropathogenic Escherichia coli growth. These results showed that nanosystem 20 could agglutinate and inhibit the bacterial growth in contrast to nanosystem 21 [24].

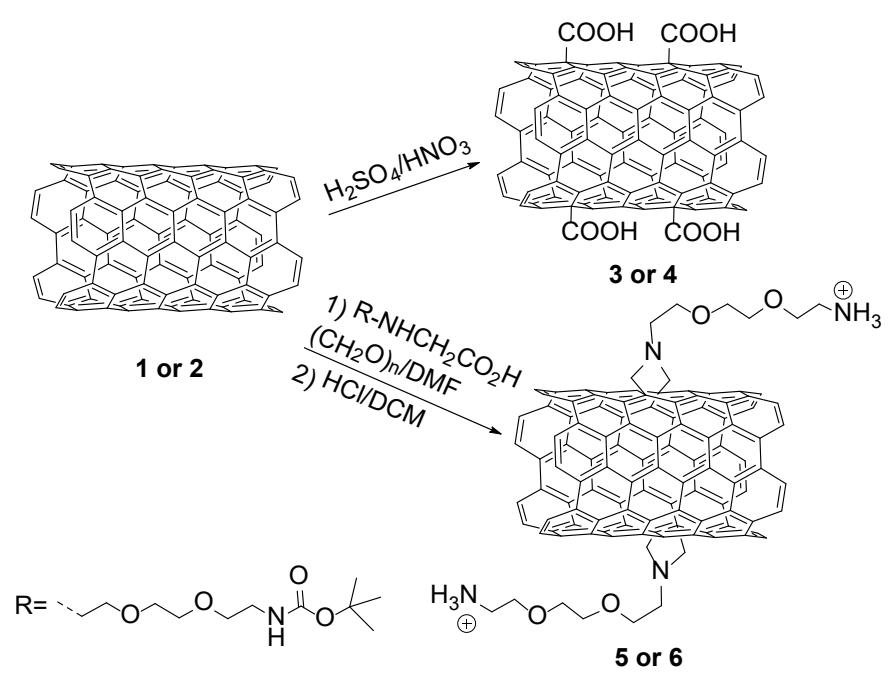

Scheme 1. Organic functionalization of CNTs

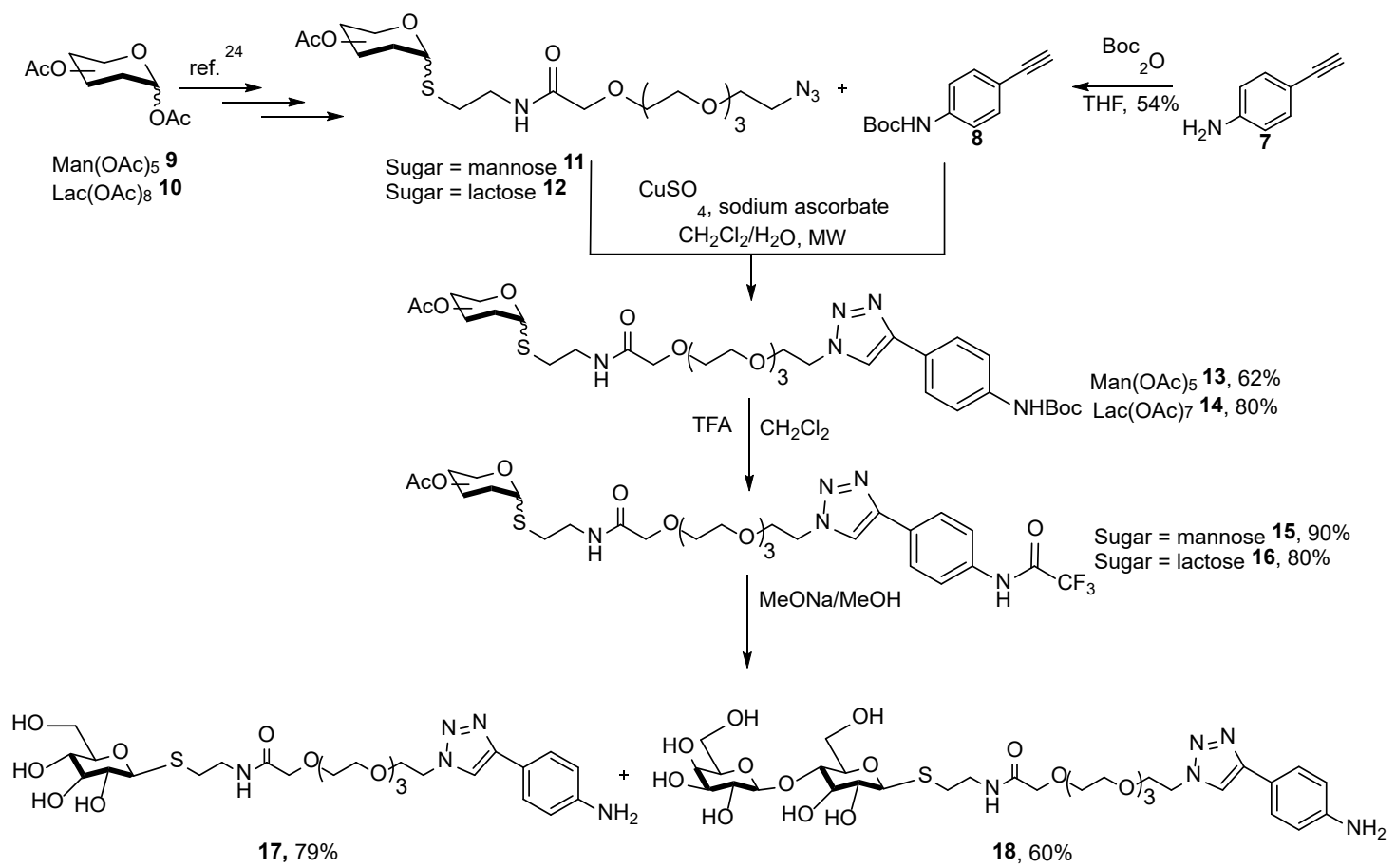

Scheme 2. The synthesis of neutral amines 17 and 18 [24] 


\section{SWCNTs-porphyrin conjugate}

At first, COOH-SWCNTs compound 3 was prepared via oxidation reaction by adding SWCNTs 1 to the mixture of concentrated $\mathrm{H}_{2} \mathrm{SO}_{4} /$ $\mathrm{HNO}_{3}$ (Scheme 4) [25].

In the second step, 5,10,15-triphenyl-20-(4-aminophenyl) porphyrin $\left(\mathrm{H}_{2}\right.$ TriMAPP) (monoaminoporphyrin) 26 was produced by the reduction reaction of 5,10,15-triphenyl-20-(4-nitrophenyl) porphyrin ( $\mathrm{H}_{2}$ TPMNPP) 25, which was synthesized through the reaction of benzaldehyde $23\left(\mathrm{C}_{7} \mathrm{H}_{6} \mathrm{O}\right), \quad p$-nitrobenzaldehyde 24 $\left(\mathrm{C}_{7} \mathrm{H}_{5} \mathrm{NO}_{3}\right)$ and Pyrrole $22\left(\mathrm{C}_{4} \mathrm{H}_{5} \mathrm{~N}\right)$ in the presence of propionic acid $\left(\mathrm{CH}_{3} \mathrm{CH}_{2} \mathrm{COOH}\right)$ under reflux condition (Scheme 5) [25].

In the third step, the acid-functionalized SWCNTs compound 3 reacted with aminoporphyrin 26 in $N, N^{\prime}$-dicyclohexylcarbodiimide (DCC) to provide the porphyrin conjugated SWCNTs 27 (Scheme
6). The interaction among the porphyrin, as an antibacterial agent, conjugated SWCNTs 27, and the bacterial cells in front of visible light cause the cell membrane ruin. Porphyrin-SWCNTs conjugates could be employed as an antibacterial agent too [25].

\section{SWCNTs functionalized by lysine}

SWCNT-Lys- $\mathrm{NH}_{2} 29$, as shown in Scheme 7 was prepared from SWCNTs 1 and $H$-Lys(Boc)-OH 28 in the presence of paraformaldehyde (PFA) and TFA to afford lysine-modified SWCNTs 29, which were nontoxic and did not have the primary influence on the microbiota [26,27].

\section{SWCNTs-ciprofloxacin as nano-antibiotic}

Ciprofloxacin 30 was reacted with di-tert-butyl dicarbonate $\left(\mathrm{Boc}_{2} \mathrm{O}\right)$ in water/dioxane including $\mathrm{NaOH}$ to provide $\mathrm{N}$-Boc-

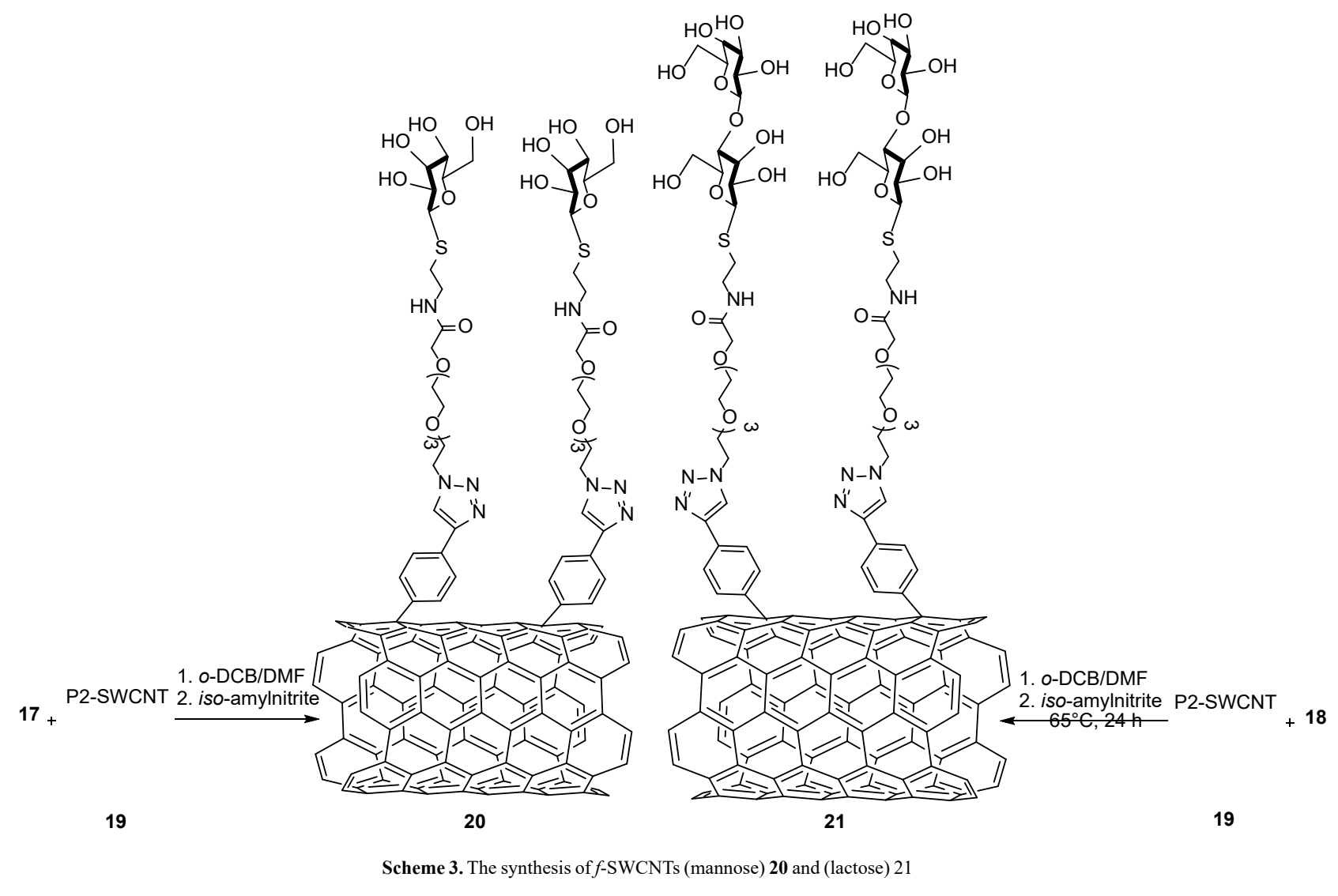



1

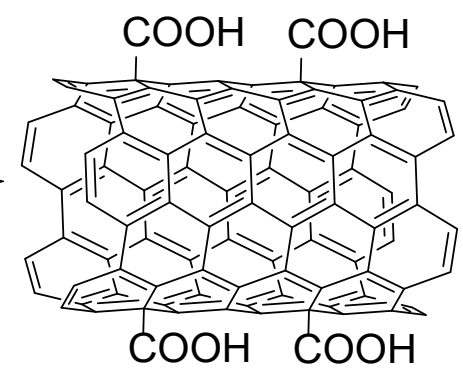

3

Scheme 4. The synthesis of the COOH-SWCNTs compound 3 




Scheme 5. The synthesis of monoaminoporphyrin 26

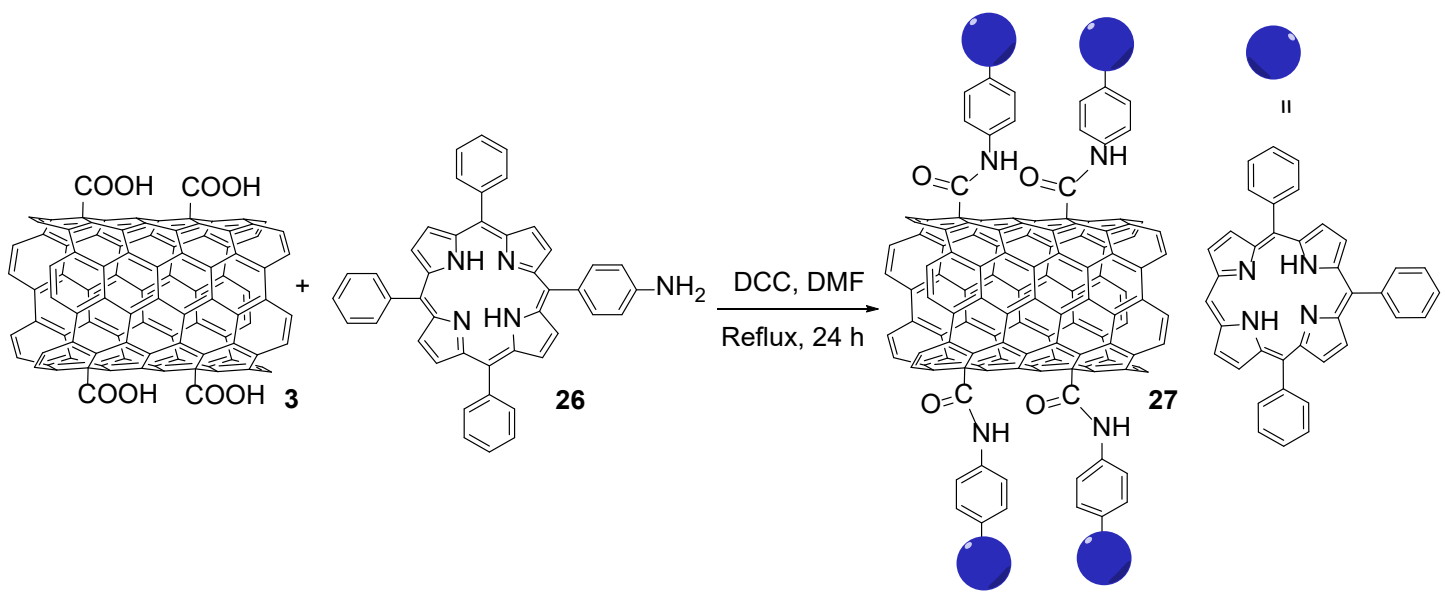

Scheme 6. The synthesis of porphyrin functionalized SWCNTs 27

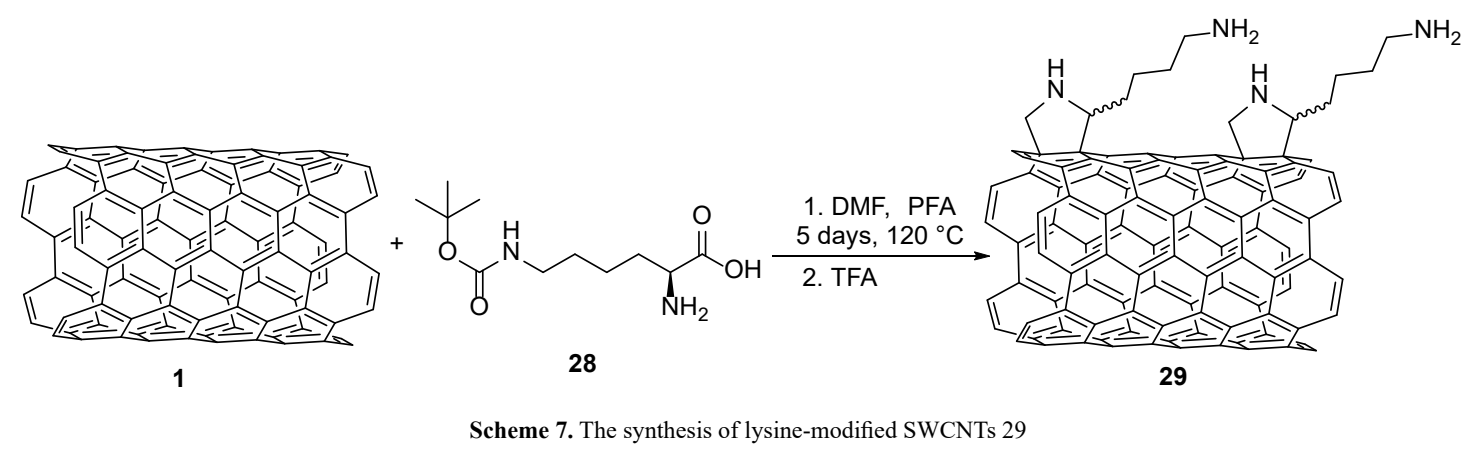

ciprofloxacin 31, which was treated with triethyleneglycol (TEG) 32 or hexaethyleneglycol (HEG) 33 in $\mathrm{CH}_{2} \mathrm{Cl}_{2}$, dimethyl aminopyridine (DMAP), and 1-ethyle-3-(3-dimethylaminopropyl)carbodiimide (EDC) to obtain $\mathrm{N}$-Boc-ciprofloxacintriethyleneglycol 35 or $\mathrm{N}$-Bocciprofloxacinhexaethyleneglycol 36 . The obtained product 35 or 36 was reacted with succinic anhydride $\left(\left(\mathrm{CH}_{2} \mathrm{CO}\right)_{2} \mathrm{O}\right) 34$ in triethylamine $\left(\mathrm{Et}_{3} \mathrm{~N}\right)$ to afford $\mathrm{N}$-CiproBoc-TEG-succinate 37 or $\mathrm{N}$-CiproBoc-HEGsuccinate 38 (Scheme 8) [28].

SWCNTs 1 was functionalized through 4-[(N-Boc)aminomethyl] aniline 39 in isoamyl nitrite $\left(\mathrm{CH}_{3}\left(\mathrm{CH}_{2}\right)_{4} \mathrm{ONO}\right)$, O-dichlorobenzene (o-DCB) and acetonitrile to provide 4 -[ $(N$-Boc $)$ aminomethyl $]$ aniline 40 , which was deprotected using TFA to yield $f$-SWCNTs 41 (Scheme 9).

$f$-SWCNTs 41 was reacted with compound 37 or 38 in DCM, EDC, and $N, N$-diisopropylethylamine (DIPEA) to obtain compound 42 or 43 , which was deprotected with TFA to afford compound 44 or 45 (Scheme 10) [28].
The main strategy was the covalent functionalization of SWCNTs with ciprofloxacin by spacer support to enhance the hydrophilichydrophobic stability and gain a fresh stable nano-antibiotic compound, which is biocompatible (Scheme 11). The antibacterial activity of $f$-SWCNTs 45 was significantly enhanced in comparison to the ciprofloxacin versus different bacteria such as $S$. aureus, $P$. aeruginosa, and E. coli [28].

\section{The synthesis of functionalized multi-walled Carbon Nanotubes ( $f$-MWCNTs) $f$-MWCNTs/polydimethylsi- loxane (PDMS)}

Joana and his co-workers prepared pristine multi-walled carbon nanotubes ( $p$-MWCNTs) 2 by chemical vapor deposition (CVD). $\mathrm{COOH}-\mathrm{MWCNTs} 4$ were prepared by chemically functionalized of p-MWCNTs 2 via oxidization with $\mathrm{HNO}_{3}$. $\mathrm{COOH}$-MWCNTs 4 was reacted with PDMS to afford $f$-MWCNTs/PDMS 46, which were used to adjust Escherichia coli adhesion (Scheme 12) [29]. 


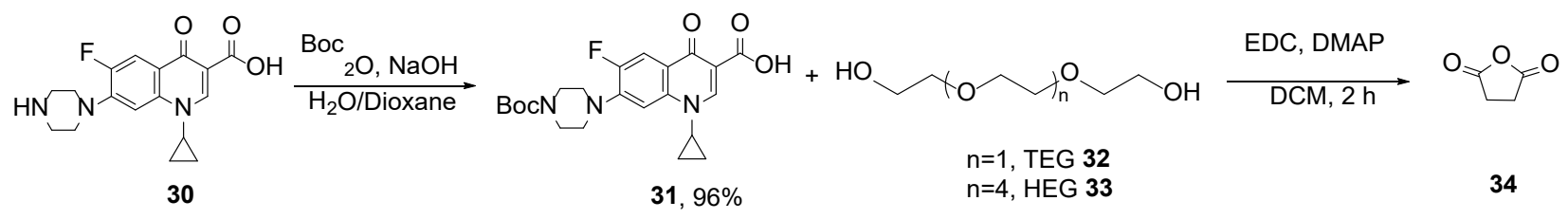

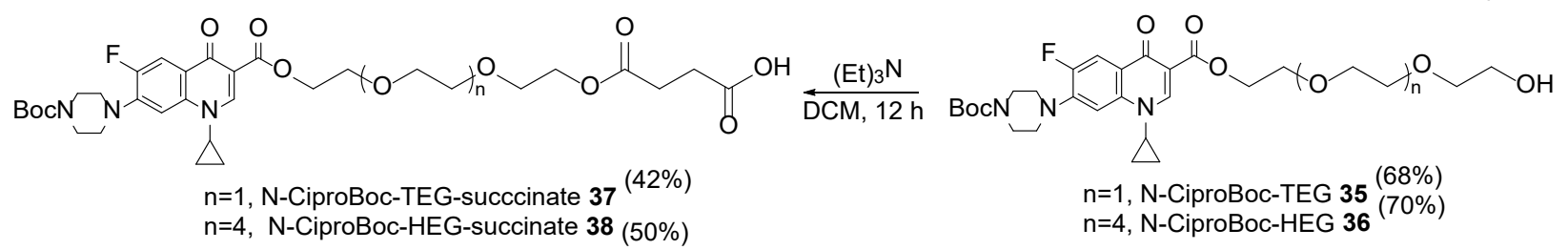

Scheme 8. The synthesis of $N$-CiproBoc-TEG-succinate 37 and $N$-CiproBoc-HEG-succinate 38

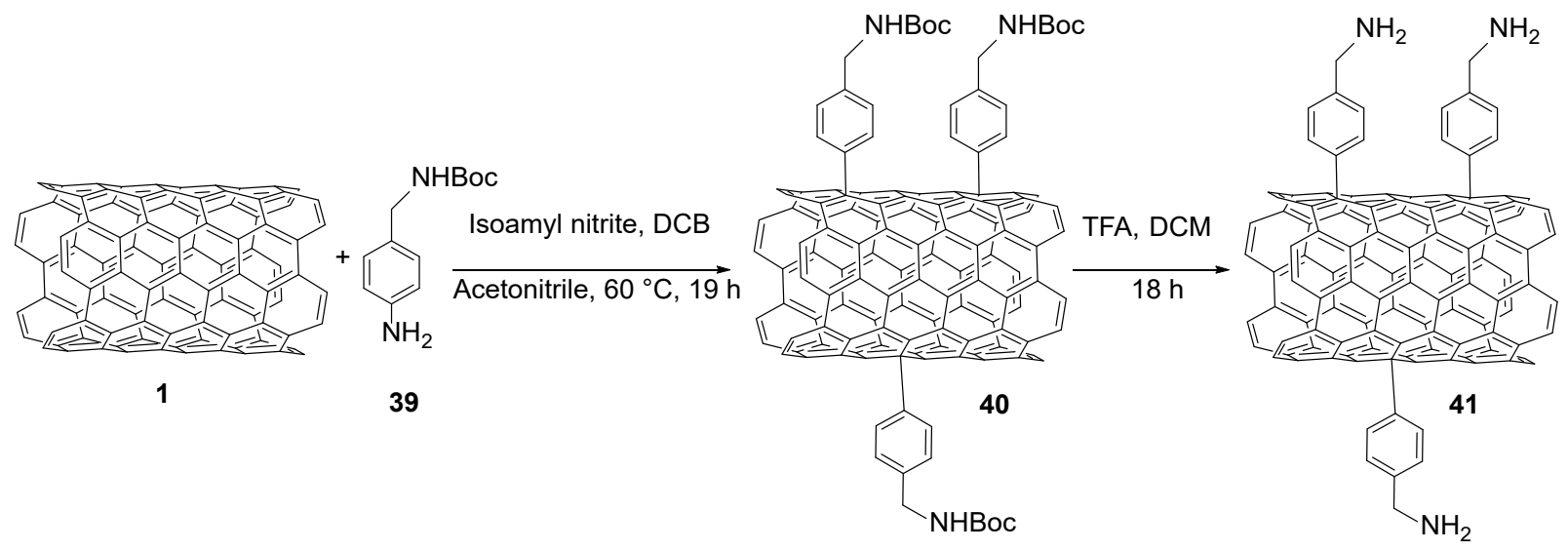

Scheme 9. The functionalization of SWCNTs

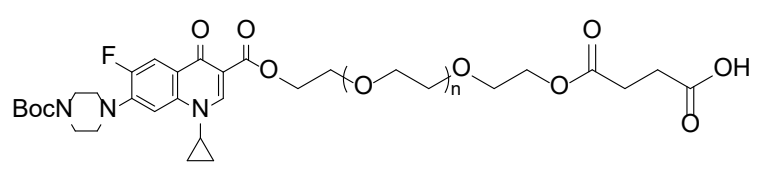

$\mathrm{n}=1$, N-CiproBoc-TEG-succcinate 37 $\mathrm{n}=4, \mathrm{~N}-$-CiproBoc-HEG-succinate $\mathbf{3 8}$

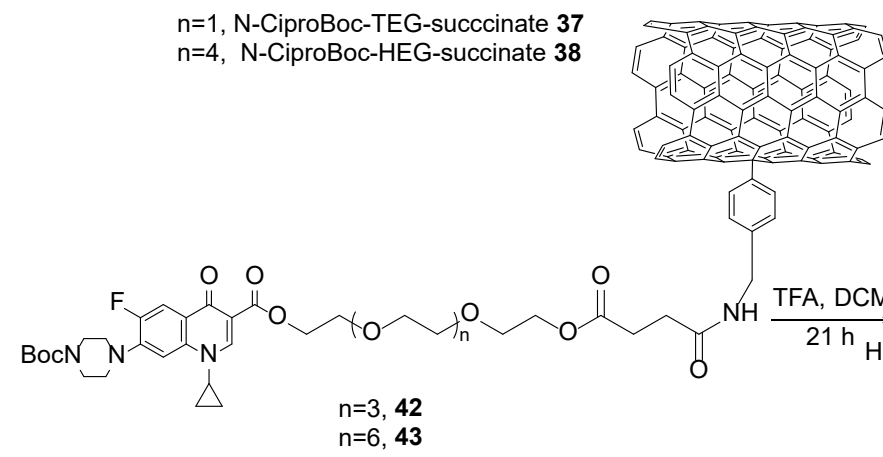

Scheme 10. The functionalization of SWCNTs with compounds 37 or 38
EDC, DIPEA

$\mathrm{DCM}, 20 \mathrm{~h}$
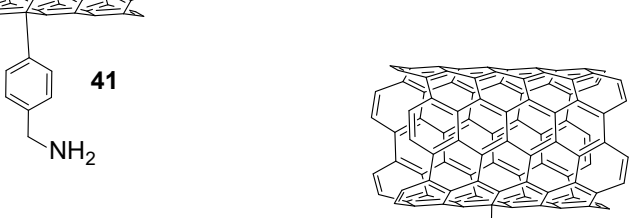


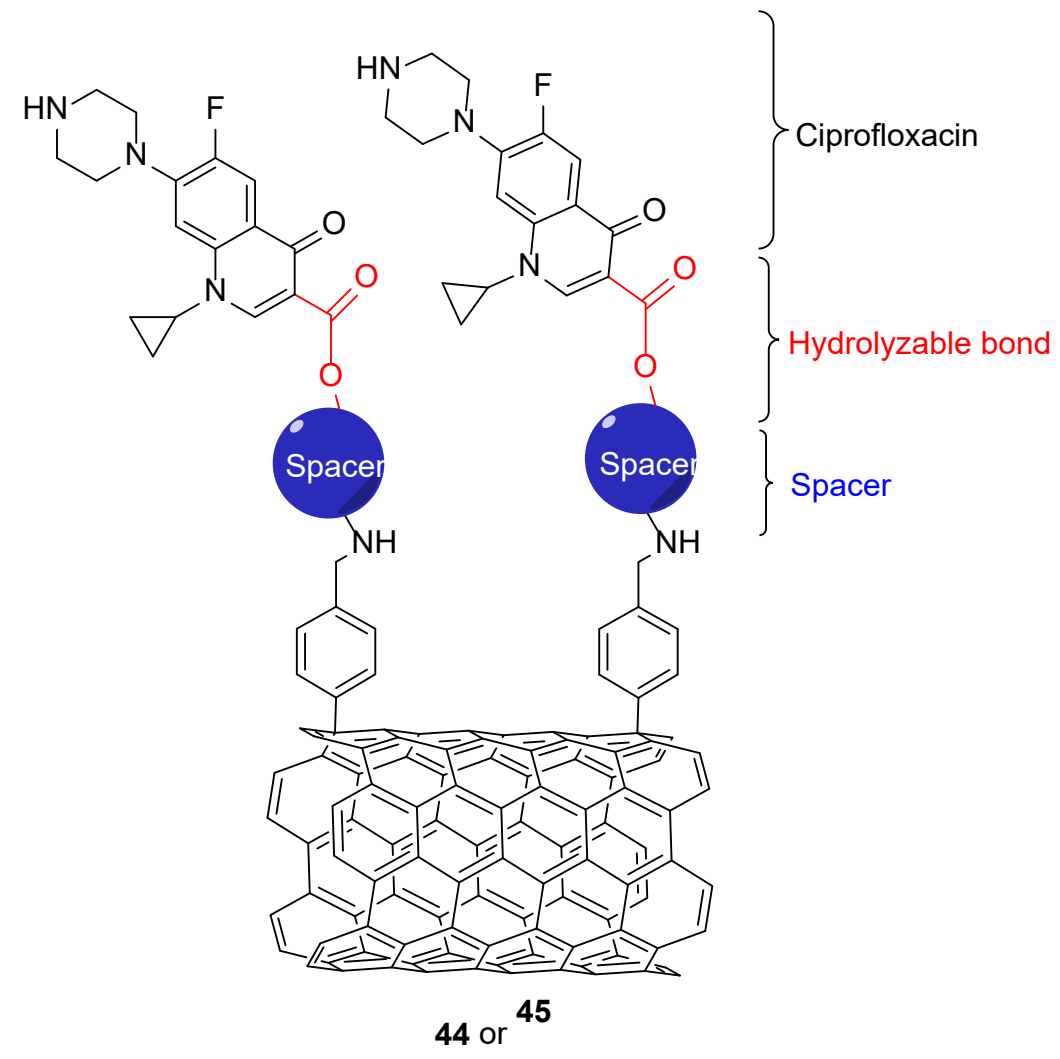

Scheme 11. The general structure of SWCNTs-ciprofloxacin 44 or 45

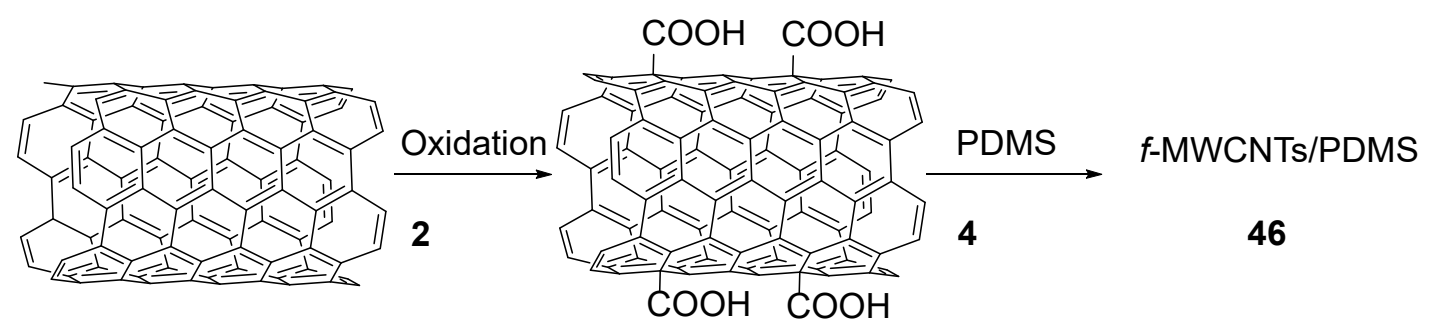

Scheme 12. The synthesis of $f$-MWCNTs/PDMS 46

\section{Methylene blue (MB) MWCNT conjugate}

COOH-MWCNTs 4 was treated with MB 47 to provide MBMWCNTs 48, which decreased the growth of E. coli and S. aureus as a useful therapeutic methodology in the combat against resilient bacterial strains (Scheme 13) [30].

\section{$\alpha$-6-deoxy-5-oxytetracycline (Doxy)-MWCNTs/ $/ \mathrm{Fe}_{3} \mathrm{O}_{4}$}

MWCNTs $/ \mathrm{Fe}_{3} \mathrm{O}_{4} 50$ was prepared by the reaction of $f$-MWCNTs (COOH-MWCNTs) 4 with $\mathrm{Fe}_{3} \mathrm{O}_{4} 49$, which was prepared in situ by the reaction of $\left(\mathrm{NH}_{4}\right)_{2} \mathrm{Fe}\left(\mathrm{SO}_{4}\right)_{2} \cdot 6 \mathrm{H}_{2} \mathrm{O}$ and $\left(\mathrm{NH}_{4}\right)_{2} \mathrm{Fe}\left(\mathrm{SO}_{4}\right)_{3} \cdot 6 \mathrm{H}_{2} \mathrm{O}$. MWCNTs/Fe3O4 50 was reacted with Doxy 51 to generate DoxyMWCNTs $/ \mathrm{Fe}_{3} \mathrm{O}_{4}$ 52, which was tested against E. coli bacteria and Bacillus subtilis (Scheme 14). The drug-release profile determined that Doxy-MWCNTs $/ \mathrm{Fe}_{3} \mathrm{O}_{4}$ conjugate has a much better ability for drug releasing than the contractual Doxy [31].

\section{Sulfamethoxazole (SMZ)-MWCNT}

Carboxylated multi-walled carbon nanotubes (f-MWCNTs) 4 were reacted with SMZ 53 as an antibiotic drug under the ultrasonic condition to form SMZ-MWCNT 54, which shows a novel way to enhance targeting in drug delivery (Scheme 15) [32-35].

\section{Malachite green (MG) MWCNT conjugate}

MGMWCNT 56 was obtained by the reaction of MG 55 and COOH-MWCNT 4, according to the reported [25] reaction previously (Scheme 16). This article presented the improved capability of a photoactivated malachite green coupled to carboxylated multi-walled CNTs (MGMWCNT) 56 for the antibacterial therapy in front of Staphylococcus aureus and Pseudomonas aeruginosa. This information indicated that the MGMWCNT conjugate 56 could be used as a further approach for removing these both bacteria structures from the medical system [36].

\section{MWCNT@LC-MIP particles}

The mixture of $f$-MWCNTs 4 and 9-vinyl-anthracene 57 (VA) in chloroform $\left(\mathrm{CHCl}_{3}\right)$ was sonicated to give the suspension 58 . Levofloxacin (LVF), methacrylic acid (MAA), ethylene glycol dimethacrylate (EDMA), and 4-methyl phenyl dicyclohexyl ethylene (MPDE) were solubilized in chloroform to provide the mixture 59. 

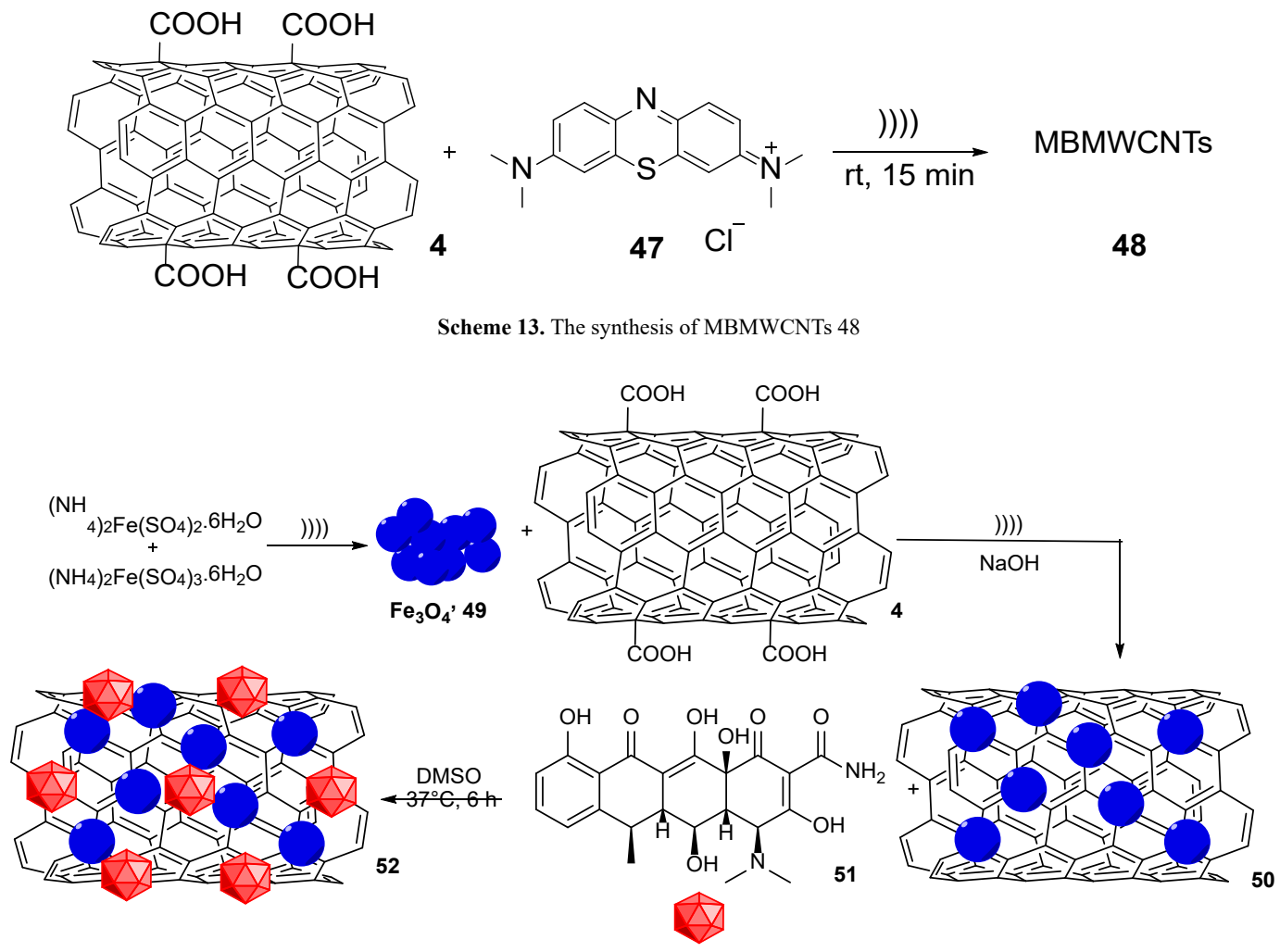

Scheme 14. The synthesis of Doxy-MWCNTs/ $/ \mathrm{Fe}_{3} \mathrm{O}_{4} 52$

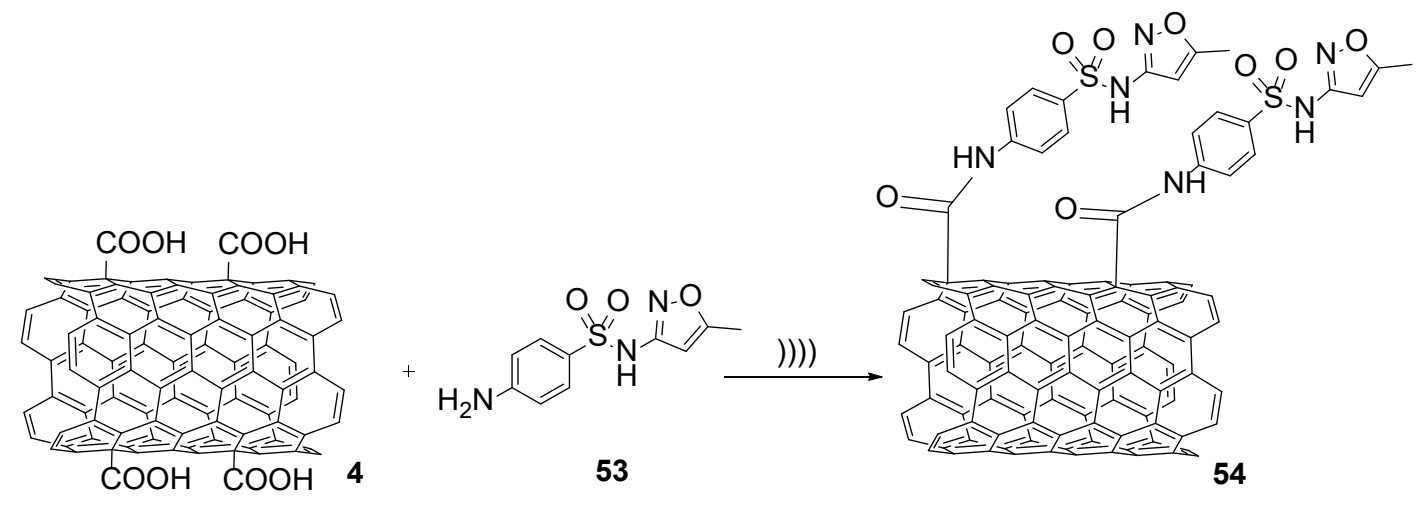

Scheme 15. The synthesis of SMZ-MWCNTs 54
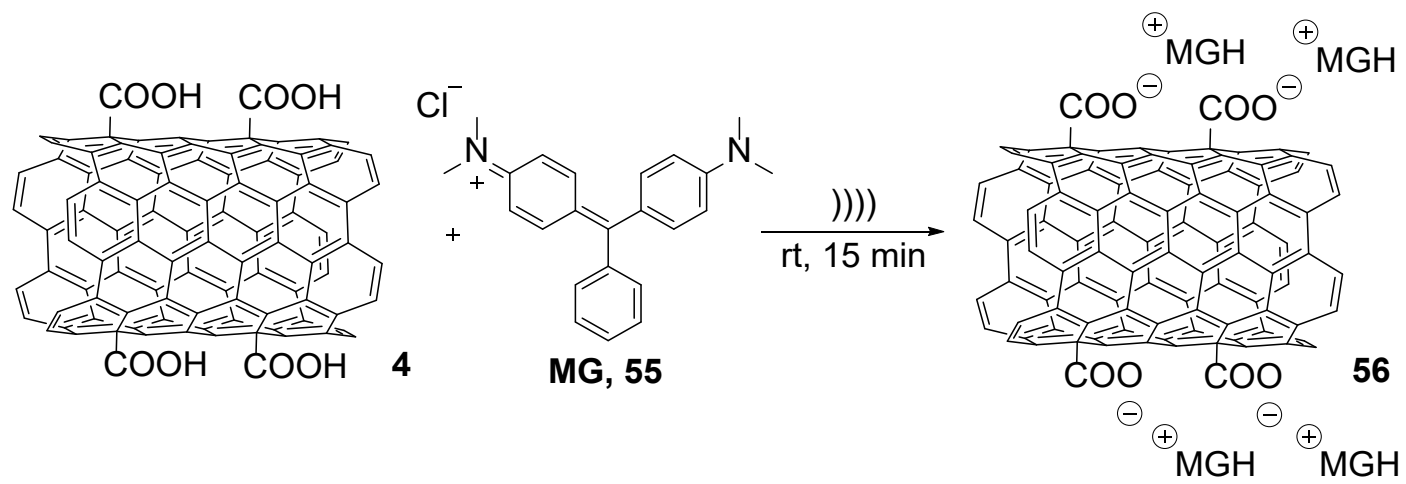

Scheme 16. The synthesis of MGMWCNT 56 
The mixtures 58 and 59 were combined and sonicated. The initiator 2,2-azobis (2-isobutyronitrile) (AIBN) was added to the mixture of reaction to start the polymerization reaction to provide MWCNT@ liquid crystalline molecularly imprinted polymers particles (MWCNT@ LC-MIP) 60, which showed better drug loading ability because of their smaller size, well permeability, and high surface area (Scheme 17). LVF is used in the infection treatment of soft tissue, skin, urinary tract, and respiratory tract. The LVF-imprinted MWCNT@LC-MIP has the potential activity for a gastro retentive drug delivery system (GRDDS) and used as a floating drug delivery systems (FDDS) [37,38].

\section{Polyethylene glycol $f$-MWCNTs/gelatin-chitosan nano compound}

$f$-MWCNTs (COOH-MWCNTs) 4 was treated with $\mathrm{SOCl}_{2}$ to give MWCNTs containing acyl chloride ( $\mathrm{RCOCl}$ ) groups 61, which was treated with polyethylene glycol 62 (PEG) to obtain polyethylene glycol $f$-MWCNTs 63 (Scheme 18). It was added into the chitosangelatin mixture under the sonicated condition to afford polyethylene glycol $f$-MWCNTs/gelatin-chitosan, which didn't demonstrate any cytotoxicity. Therefore, the ciprofloxacin lactate drug mixture was appended to MWCNTs-COOH/gelatin-chitosan nano compound and MWCNTs-PEG/gelatin-chitosan nano compound to evaluate their antibiotic activities. It can be used as an agent in nanomedicine, targeted thermic tumor ruin, drug delivery, and magnetic battlefield targeting of tumors. It is evident that the transfer of antibiotic drugs like ciprofloxacin can be easily made when it was instantly immobilized on the carbon nanotube surface through $H$-bonding and $\pi-\pi$ stacking [39].

\section{MWCNTs-magnetic nanoparticles}

In this process, MWCNTs were reacted with concentrated $\mathrm{H}_{2} \mathrm{SO}_{4} / \mathrm{HNO}_{3}$ to provide $\mathrm{COOH}-\mathrm{MWCNTs}$, which were mixed with $\mathrm{FeCl}_{3} \cdot 6 \mathrm{H}_{2} \mathrm{O}$ in ethylene glycol and sodium acetate $\left(\mathrm{C}_{2} \mathrm{H}_{3} \mathrm{NaO}_{2}\right)$ to provide MWCNTs-magnetic NPs under ultrasonic condition through an easy one-step high-temperature decomposition method [40,41]. In conclusion, CNTs-Magnetic NPs had a great application in the rapid, efficient sample pretreat for polyether ionosphere antibiotic drugs and $S$-triazine antiparasitics in eatable food for animals [42].

\section{MWCNTs-coated titanium alloy discs:}

MWCNTs-coated titanium alloy discs were prepared through the coating of MWCNTs by the hard titanium alloy discs (TiAl6V4), and then immobilizing the encapsulated $\mathrm{Ni}$ particles on the MWCNTs surface. Rifampicin is an antibiotic drug which was loaded on the MWCNTs-coated titanium alloy discs to inhibit biofilm formation against Staphylococcus epidermidis [43].

\section{Carboxymethyl chitosan (CMCS)-MWCNTs}

Chitosan and $\mathrm{NaOH}$ in isopropanol $\left(\mathrm{C}_{3} \mathrm{H}_{8} \mathrm{O}\right)$ as a solvent was put into a flask to alkalize. Monochloroacetic acid (MCA) was solubilized in isopropanol, and added to the reaction mixture to provide CMCS 64 [44]. The mixture of MWCNTs 2 and CMCS 64 were sonicated to afford a homogeneous CMCS-MWCNT 65, which was poured in $\mathrm{MeOH}$ to obtain the solid nano bio-compound 65 (Scheme 19) [45]. These nanocomposites display greater antibacterial activity in front of $S$. aureus and E. coli than the employed standard ampicillin (a penicillin antibiotic) and gentamicin [46].

\section{The synthesis of both functionalized MWCNTs and SWCNTs}

\section{Electro-conductive CNT hybrid hydrogels}

CNTs were produced by aerosol-assisted chemical vapor deposition [47]. Hydrogel including different quantities of CNT, $\mathrm{H}_{\mathrm{NTi}}(\mathrm{i}=1,2$, 3 ), were produced under SONOPULS method by mixing proper CNT mass in a Gel water mixture 66 [48]. Acrylamide (AAm) 67, polyethylene glycol dimethacrylate (PEGDMA) 68, and ammonium

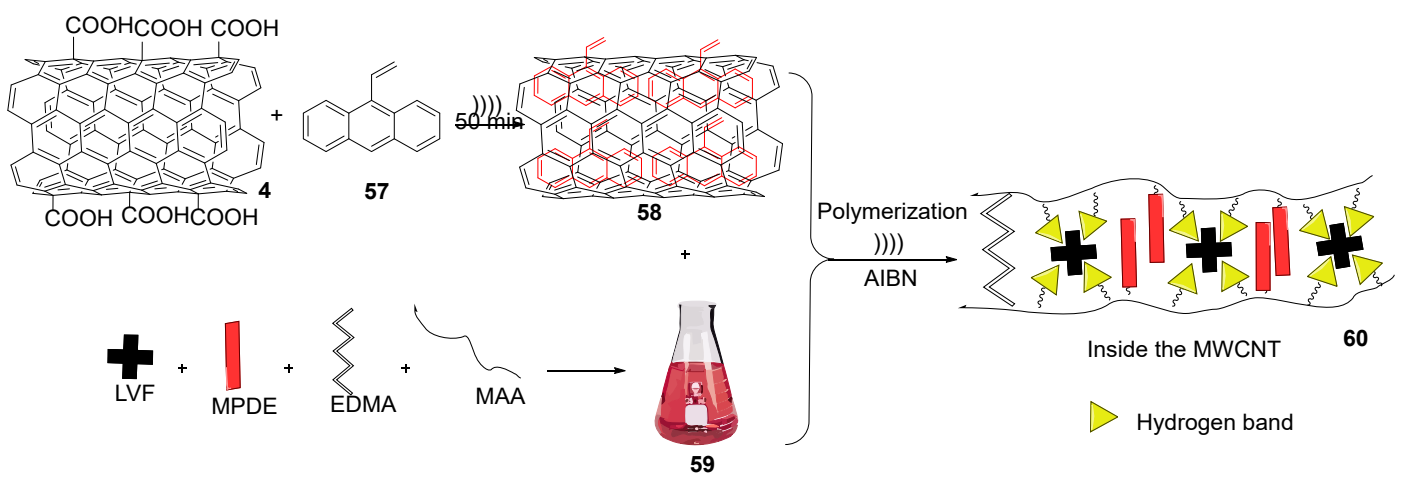

Scheme 17. The synthesis of MWCNT@LC-MIP 60

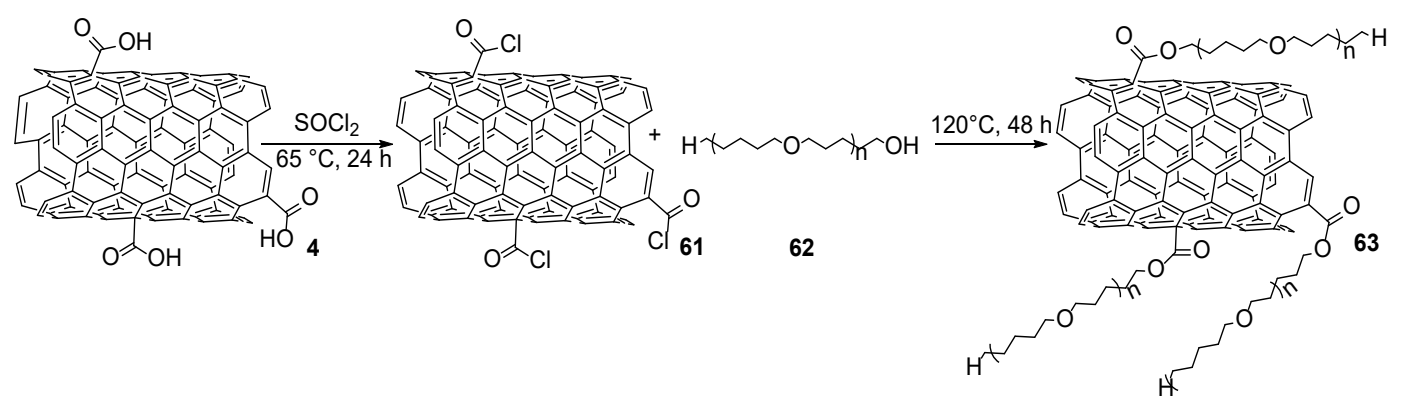

Scheme 18. The synthesis of polyethylene glycol $f$-MWCNTs 63 
persulfate $\left(\left(\mathrm{NH}_{4}\right)_{2} \mathrm{~S}_{2} \mathrm{O}_{8}\right) 69$ were added to the mixture 66 to provide the polymerization solution 70 , which was put among two $5.0 \times 5.0$ $\mathrm{cm}^{2}$ glass sheets, disconnected with a Teflon spacer $(0.6 \mathrm{~mm})$ to obtain electro-conductive CNT hybrid hydrogels 71 (Scheme 20). The design of electro-conductive CNT hybrid hydrogels could release curcumin (CUR) as an antibiotic drug, which was applied to extraneous voltage as a valuable device for wound curing. The existence of gelatin in the reaction feed is forced to improve the dispersibility of CNT in liquid media $[49,50]$.

\section{Human serum albumin (HSA)-CNTs}

CNTs were oxidized using $\mathrm{H}_{2} \mathrm{SO}_{4} / \mathrm{HNO}_{3}$ under the ultrasonic condition to provide $\mathrm{COOH}-\mathrm{CNT}$. In this process, the phosphate buffer was used to dissolve HSA, which was added to $\mathrm{COOH}-\mathrm{CNTs}$ solution to obtain HSA-CNTs [51]. HSA can facilitate binding and carrying a lot of poorly soluble antibiotic drugs like bendroflumethiazide in water [52].

\section{Star-shaped poly( $\varepsilon$-caprolactone) (PCL)-poly(ethylene glycol) (PEG)/CNTs ${ }_{\mathrm{p} \text { red. ocl }}$ nano compound}

CNTs were synthesized using Fe as the catalyst via CVD method [53]. CNTs were functionalized to immobilize some kinds of chemical groups such as $\mathrm{OH}, \mathrm{COOH}$, and $\mathrm{RCOCl}$ on their surface through threesteps. The first step, the CNTs were reacted with nitric acid under reflux condition to provide partly oxidized CNTs to produce $\mathrm{OH}$ and $\mathrm{COOH}$ groups. In the second step, carboxyl groups $(\mathrm{COOH})$ of $\mathrm{CNTs}_{\mathrm{p} \text { oxi }}$ were reduced chemically by $\mathrm{LiAlH}_{4}$ to promote the hydroxyl groups to afford $\mathrm{CNTs}_{\mathrm{p} \text { red }}$, which were treated with $\mathrm{OxCl}$ to obtain $\mathrm{CNTs}_{\mathrm{p} \text { red-OCl }} 72$ (Scheme 21). In the last step, CNTs $s_{\mathrm{p} \text { red-OCl }}$ were utilized to produce the star-like PCL-PEG/CNTs $s_{p \text { red-OCl }}$ nano compounds as below. The CNTs red-OCl 72 were mixed with prepared star-like PCL-PEG copolymers 73 , which was prepared by relatively modifying a chemical three-step method [54]. At first, a homopolymer of star-like PCL was produced by $\varepsilon$-caprolactone ( $\varepsilon$-CL), pentaery-thritol (PTOL), and stannous octoate $\left(\mathrm{SnOct}_{2}\right)$ under reflux condition. In the second step, a prepolymer of star-like PCL-OxCl was obtained by the treatment of OH groups of starlike PCL (stPCL) and acyl chloride (RCOCl) groups of oxalyl chloride $(\mathrm{OxCl})$ under reflux condition. In the next step, a mixture of PEG in dichloromethane was added to avoid unwanted cross-linking reacting over the prepolymer preparation to provide star-like PCL-PEG, which was reacted with CNTs ${ }_{\text {p red-OCl }}$ to afford star-like PCL-PEG/CNTs nano compound 74 (Scheme 22). Also, the resulting product was tested against Staphylococcus aureus bacteria and Pseudomonas aeruginosa. So, thermal and several mechanical features of nano compounds 74

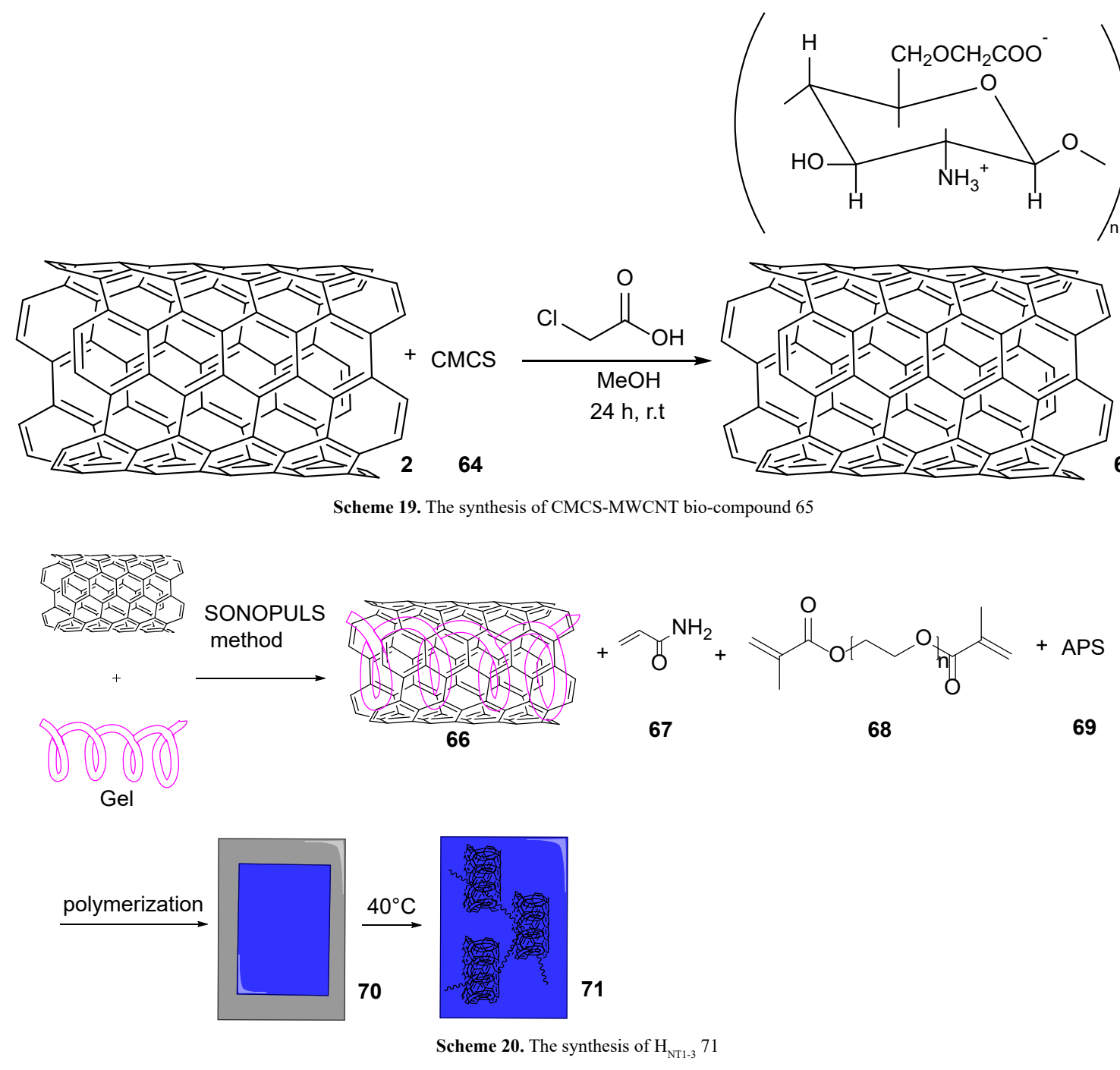






Scheme 21. The chemical framework of CNTs p red-OCl 72



StPCL-PEG $\frac{\mathrm{DCM}}{\mathrm{N}_{2}, 50{ }^{\circ} \mathrm{C}}$

73



Scheme 22. The synthesis of star-like PCL-PEG/CNTs $s_{\text {prd-ocl }}$ nano compounds 74

were better than the polymeric compound, while their bacterial action was lesser. The molecular scaffold of the star-like copolymer made conceivable poly(ethylene glycol) chains be used to the achievement of bacteria and inhibited their growth [55].

\section{Conclusion}

In conclusion, the role of carbon nanotubes in antibiotics drug delivery was reviewed through the functionalization of SWCNTs and MWCNTs to improve their abilities such as drug-releasing, targeting, adsorption, solubility in water. Consequently, $f$-SWCNTs and $f$-MWCNTs display better antibacterial activity against bacteria like $E$. coli, S. aureus, Bacillus subtilis, and etc.

\section{Acknowledgments}

The authors are thankful for the support of the Research Council of Alzahra University and the University of Tehran.

\section{References}

1. Bin Sheng Wong, Sia Lee Yoong, Anna Jagusiak, Tomasz Panczyk, Han Kiat Ho (2013) Carbon nanotubes for delivery of small molecule drugs. Adv Drug Deliv Rev 65: $1964-$ 2015. [Crossref]

2. Iijima S (1991) Helical microtubules of graphitic carbon. Nature 354: 56-58.

3. Ichihashi T, Iijima S (1993) Single-shell carbon nanotubes of 1-nm diameter. Nature 363: 603-605. 
4. Yu MF, Lourie O, Dyer MJ, Moloni K, Kelly TF (2000) Strength and breaking mechanism of multiwalled carbon nanotubes under tensile load. Science 287: 637-640.

5. Lacerda L, Bianco A, Prato M, Kostarelos K (2006) Carbon nanotubes as nanomedicines: From toxicology to pharmacology. Adv Drug Deliv Rev 58: 1460-1470.

6. Kaittanis C, Santra S, and Perez JM (2010) Emerging nanotechnology-based strategies for the identification of microbial pathogenesis. Adv Drug Deliv Rev 62: 408-423.

7. Bianco A, Kostarelos K, and Prato M (2005) Applications of carbon nanotubes in drug delivery. Curr Opin Chem Biol 9: 674-679.

8. Malekmohammadi S, Hadadzadeh H, Rezakhani S, Amirghofran Z (2019) Design and synthesis of gatekeeper coated dendritic silica/titania mesoporous nanoparticles with sustained and controlled drug release properties for targeted synergetic chemosonodynamic therapy. ACS BIOMATER-SCI ENG 5: 4405-4415.

9. Allen TM, Cullis PR (2004) Drug delivery systems: entering the mainstream. Science 303: $1818-1822$

10. Liu J, Rinzler AG, Dai H, Hafner JH, Bradley RK, et al. (1998) Fullerene pipes. Science 280: $1253-1256$

11. Georgakilas V, Kordatos K, Prato M, Guldi DM, et al. (2002) Organic functionalization of carbon nanotubes. J Am Chem Soc 124: 760-761.

12. Georgakilas V, Tagmatarchis N, Pantarotto D, Bianco A, Briand JP (2002) Amino acid functionalisation of water soluble carbon nanotubes. Chem Comm 3050-3051.

13. Zhu X, Radovic-Moreno AF, Wu J, Langer R, and Shi J (2014) Nanomedicine in the management of microbial infection-overview and perspectives. Nano today 9: 478498.

14. Santos RS, Figueiredo C, Azevedo NF, Braeckmans K, De Smedt SC (2018) Nanomaterials and molecular transporters to overcome the bacterial envelope barrier: Towards advanced delivery of antibiotics. Adv Drug Deliv Rev 28-48.

15. Mohammadi Ziarani G, Malmir M, Lashgari N, Badiei A (2019) The role of hollow magnetic nanoparticles in drug delivery. RSC adv 9: 25094-25106.

16. Vavsari VF, Mohammadi Ziarani G, Badiei A (2015) The role of SBA-15 in drug delivery. $R S C A d v$ 5: 91686-91707.

17. F. Mohajer, G. Mohammadi Ziarani, and A. Badiei, New advances on Au-magnetic organic hybrid core-shells in MRI, CT imaging, and drug delivery. RSC Advances 11 (2021) 6517-6525.

18. Rahimifard M, Mohammadi Ziarani G, Badiei A, Asadi S, Soorki AA (2016) Onepot solvent-free synthesis of 1,8-dioxo-octahydroxanthene derivatives using sulfonic acid-functionalized LUS-1 and their antimicrobial activities. Res Chem Intermed 42 : 3847-3861.

19. Mohammadi Ziarani G, Hassanzadeh Z, Gholamzadeh P, Asadi S, Badiei A (2016) Advances in click chemistry for silica-based material construction. RSC Adv 6: 2197922006 .

20. Mohammadi Ziarani G, Asadi S, Badiei A, Sharifi A, Amanlou M (2016) Synthesis of Some Spiro Indeno [1, 2-b] pyrido [2, 3-d] Pyrimidine-5, 3'-Indolines as New Urease Inhibitors. IJPR 15: 55. [Crossref]

21. Mohammadi Ziarani G, Faramarzi S, Asadi S, Badiei A, Bazl R, Amanlou M (2013) Three-component synthesis of pyrano [2,3-d]-pyrimidine dione derivatives facilitated by sulfonic acid nanoporous silica (SBA-Pr-SO $3 \mathrm{H}$ ) and their docking and urease inhibitory activity. DARU 21:3.

22. Mohammadi Ziarani G, Mofatehnia P, Mohajer F, and Badiei A (2020) Rational Design Yolk-Shell Nanostructures for Drug Delivery. RSC Adv. In press.

23. Romero-Ben E, Cid JJ, Assali M, Fernández-García E, Wellinger RE (2019) Surface modulation of single-walled carbon nanotubes for selective bacterial cell agglutination. Int J Nanomedicine 14: 3245-3263.

24. Leal MP,Assali M, Cid J, Valdivia V, Franco J (2015) Synthesis of 1D-glyconanomaterials by a hybrid noncovalent-covalent functionalization of single wall carbon nanotubes: a study of their selective interactions with lectins and with live cells. Nanoscale 7: 19259-19272.

25. Sah U, Sharma K, Chaudhri N, Sankar M, Gopinath P (2018) Antimicrobial photodynamic therapy: Single-walled carbon nanotube (SWCNT)-Porphyrin conjugate for visible light mediated inactivation of Staphylococcus aureus. Colloids Surf B 162: 108-117.

26. Mulvey JJ, Feinberg EN, Alidori S, McDevitt MR, Heller DA (2014) Synthesis, pharmacokinetics, and biological use of lysine-modified single-walled carbon nanotubes. Int J Nanomedicine 9: 4245.
27. Mulvey JJ, Littmann ER, Ling L, McDevitt MR, Pamer EG (2018) The effects of amine-modified single-walled carbon nanotubes on the mouse microbiota. Int $J$ Nanomedicine 13: 5275-5286.

28. Assali M, Zaid AN, Abdallah F, Almasri M, Khayyat R (2017) Single-walled carbon nanotubes-ciprofloxacin nanoantibiotic: Strategy to improve ciprofloxacin antibacteria activity. Int J Nanomedicine 12: 6647-6659. [Crossref]

29. Vagos MR, Moreira JMR, Soares OSGP, Pereira MFR, Mergulhão FJ (2019) Incorporation of carbon nanotubes in polydimethylsiloxane to control Escherichia coli adhesion. Polym Compos 40: E1697-E1704

30. Parasuraman P, Anju VT, Sruthil Lal SB, Sharan A, Busi S (2019) Synthesis and antimicrobial photodynamic effect of methylene blue conjugated carbon nanotubes on E. coli and S. aureus. PPS 18: 563-576.

31. Ghoderao P, Sahare S, Alegaonkar P, Kulkarni AA, Bhave T (2019) Multiwalled carbon nanotubes decorated with $\mathrm{Fe} 3 \mathrm{O} 4$ Nanoparticles for efficacious doxycycline delivery. ACS Appl Nano Mater 2: 607-616.

32. Wu Z, Wang Z, Yu F, Thakkar M, Mitra S (2017) Variation in chemical, colloidal and electrochemical properties of carbon nanotubes with the degree of carboxylation. $J$ Nanopart Res 19: 16.

33. Wang Z, Wu Z, Di Benedetto G, Zunino III JL, Mitra S (2015) Microwave synthesis of highly oxidized and defective carbon nanotubes for enhancing the performance of supercapacitors. Carbon 91: 103-113.

34. Wu Z, Hamilton Jr RF, Wang Z, Holian A, Mitra S (2014) Oxidation debris in microwave functionalized carbon nanotubes: Chemical and biological effects. Carbon 68: 678-686.

35. Chen K, Mitra S (2019) Incorporation of functionalized carbon nanotubes into hydrophobic drug crystals for enhancing aqueous dissolution. Colloids Surf B 173 386-391.

36. Anju VT, Paramanantham P, Siddhardha B, Lal SBS, Sharan A (2019) Malachite greenconjugated multi-walled carbon nanotubes potentiate antimicrobial photodynamic inactivation of planktonic cells and biofilms of pseudomonas aeruginosa and staphylococcus aureus. Int J Nanomedicine 14: 3861-3874.

37. Zhang LP, Tan XX, Huang YP, Liu ZS (2018) Floating liquid crystalline molecularly imprinted polymer coated carbon nanotubes for levofloxacin delivery. Eur J Pharm Biopharm 127: 150-158.

38. Zhang LP, Wang XL, Pang QQ, Huang YP, Tang L (2017) Solvent-responsive floating liquid crystalline-molecularly imprinted polymers for gastroretentive controlled drug release system. Int J Pharm 532: 365-373.

39. Sharmeen S, Rahman AFMM, Lubna MM, Salem KS, Islam R (2018) Polyethylene glycol functionalized carbon nanotubes/gelatin-chitosan nanocomposite: An approach for significant drug release. Bioact Mater 3: 236-244.

40. Xu Y, Ding J, Chen H, Zhao Q, Hou J (2013) Fast determination of sulfonamides from egg samples using magnetic multiwalled carbon nanotubes as adsorbents followed by liquid chromatography-tandem mass spectrometry. Food Chem 140: 83-90.

41. Morales-Cid G, Fekete A, Simonet BM, Lehmann R, Cárdenas S (2010) In situ synthesi of magnetic multiwalled carbon nanotube composites for the clean-up of (Fluoro) quinolones from human plasma prior to ultrahigh pressure liquid chromatography analysis. Analytical Chemistry 82: 2743-2752. [Crossref]

42. Liu X, Xie S, Ni T, Chen D, Wang X (2017) Magnetic solid-phase extraction based on carbon nanotubes for the determination of polyether antibiotic and s-triazine drug residues in animal food with LC-MS/MS. J Sep Sci 40: 2416-2430.

43. Hirschfeld J, Akinoglu EM, Wirtz DC, Hoerauf A, Bekeredjian-Ding I (2017) Longterm release of antibiotics by carbon nanotube-coated titanium alloy surfaces diminish biofilm formation by Staphylococcus epidermidis. Nanomedicine 13: 1587-1593.

44. Chen XG, Park HJ (2003) Chemical characteristics of O-carboxymethyl chitosans related to the preparation conditions. Carbohydr Polym 53: 355-359.

45. Venkatesan J, Jayakumar R, Mohandas A, Bhatnagar I, Kim SK (2014) Antimicrobia activity of chitosan-carbon nanotube hydrogels. Materials 7: 3946-3955.

46. El-Ghany NAA (2017) Antimicrobial activity of new carboxymethyl chitosan-carbon nanotube biocomposites and their swell ability in different $\mathrm{pH}$ media. $J$ Carbohydr Chem 36: 31-44.

47. Cirillo G, Caruso T, Hampel S, Haase D, Puoci F (2013) Novel carbon nanotube composites by grafting reaction with water-compatible redox initiator system. Colloid Polym Sci 291: 699-708.

48. Castro Nava A, Cojoc M, Peitzsch C, Cirillo G, Kurth I (2015) Development of novel radiochemotherapy approaches targeting prostate tumor progenitor cells using nanohybrids. Int J Cancer 137: 2492-2503. 
49. Tasis D, Tagmatarchis N, Bianco A, Prato M (2006) Chemistry of carbon nanotubes. Chem Rev 106: 1105-1136.

50. Cirillo G, Curcio M, Spizzirri UG, Vittorio O, Tucci P (2017) Carbon nanotubes hybrid hydrogels for electrically tunable release of Curcumin. Eur Polym J 90: 1-12.

51. Hosseinzadeh M, Nikjoo S, Zare N, Delavar D, Beigoli S (2019) Characterization of the structural changes of human serum albumin upon interaction with single-walled and multi-walled carbon nanotubes: spectroscopic and molecular modeling approaches. Res Chem 45: 401-423.

52. Pang YH, Yang LL, Shuang SM, Dong C, Thompson M (2005) Interaction of human serum albumin with bendroflumethiazide studied by fluorescence spectroscopy. $J$ Photochem and Photobiol B 80: 139-144. [Crossref]
53. Silva-Jara J, Manríquez-González R, López-Dellamary F, Puig J, Nuño-Donlucas S (2015) Semi-continuous heterophase polymerization to synthesize nanocomposites of poly (acrylic acid)-functionalized carbon nanotubes. J Macromol Sci A 52: 732-744.

54. Tinajero-Díaz E, Guerrero-Ramírez L, Manríquez-González R, Martínez-Richa A Nuño-Donlucas S (2014) Star-Shaped Poly ( $\varepsilon$-caprolactone)-co-poly (ethylene glycol) Synthesized with Oxalyl Chloride as Linker Molecule. J Macromol Sci A 51: 499-510.

55. Cajero-Zul LR, López-Dellamary FA, Gómez-Salazar S, Vázquez-Lepe M, VeraGraziano R (2019) Evaluation of the resistance to bacterial growth of star-shaped poly(e-caprolactone)-co-poly(ethylene glycol) grafted onto functionalized carbon nanotubes nanocomposites. J Biomater Sci Polym Ed 30: 163-189. [Crossref]

Copyright: (2021 Mohammadi Ziarani G. This is an open-access article distributed under the terms of the Creative Commons Attribution License, which permits unrestricted use, distribution, and reproduction in any medium, provided the original author and source are credited. 